\title{
Chronic Plasmodium vivax infection in a patient with splenomegaly and severe thrombocytopenia
}

\author{
Infecção crônica por Plasmodium vivax em paciente \\ com esplenomegalia e plaquetopenia grave
}

\section{Marcus Vinícius Guimarães de Lacerda ${ }^{1,2,3}$, Janayna Roriz Hipólito ${ }^{1}$ and Leny Nascimento da Motta Passos ${ }^{2,3,4}$}

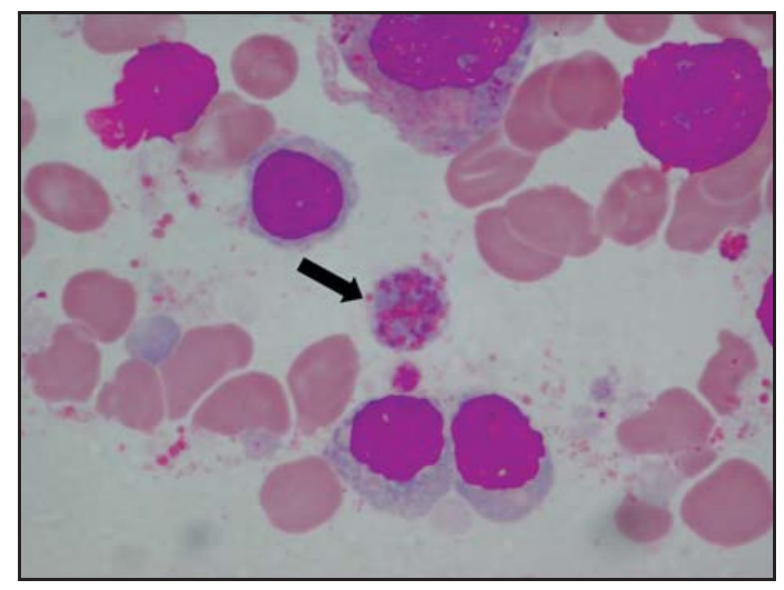

$\mathbf{A}$

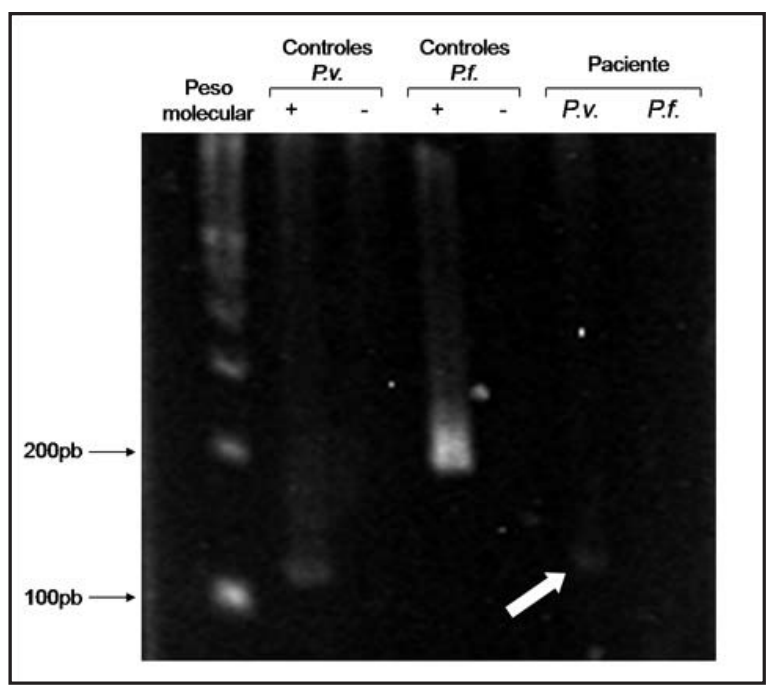

B

1. Fundação de Medicina Tropical do Amazonas, Manaus, AM. 2. Universidade do Estado do Amazonas, Manaus, AM. 3. Centro Universitário Nilton Lins, Manaus, AM 4. Fundação de Hematologia e Hemoterapia do Amazonas, Manaus, AM.

Address to: Dr. Marcus Vinícius Guimarães de Lacerda. FMT-AM. Av. Pedro Teixeira 25, Bairro Dom Pedro, 69040-000 Manaus, AM.

Telefax: $55923656-0620$

e-mail: marcuslacerda@uol.com.br

Recebido para publicação em 24/06/2008

Aceito em 01/09/2008 
A previously healthy 14-year-old patient from Maués (State of Amazonas) started with daily high fever in December 2004. After one month of disease, the fever became intermittent and the patient became afebrile in February 2005. Several thick blood smears were negative for malaria. There was marked splenomegaly on physical examination. Abdominal ultrasound and computed tomography showed homogenous enlargement of the liver and spleen. The blood analysis results were: hemoglobin, $10 \mathrm{~g} / \mathrm{dl}$; leukocytes, $4,800 / \mathrm{mm}^{3}$ (with atypical lymphocytes); platelets, $6,000 / \mathrm{mm}^{3}$; reticulocytes, $0.3 \%$; erythrocyte sedimentation rate, $68 \mathrm{~mm}$ in the first hour; and normal biochemistry. Repeated thick blood smears and $\mathrm{QBC}^{\circledR}$ for malaria were again negative. A bone marrow biopsy performed in March 2005 showed myeloid and megakaryocytic hyperplasia, without any evidence of hemophagocytic syndrome. During this period, the platelet counts ranged from 3,000 to $24,000 / \mathrm{mm}^{3}$, but the patient did not report any bleeding episodes. A new bone marrow analysis performed in May 2005 showed rare Plasmodium vivax schizonts inside red blood cells (Figure A). In order to confirm the species involved by means of molecular biology, nested PCR was performed on a peripheral blood sample, which showed a 120-bp band typical of Plasmodium vivax, on the electrophoresis gel (Figure B). The patient was started on chloroquine $(10 \mathrm{mg} / \mathrm{kg}$ on day $1 ; 7.5 \mathrm{mg} / \mathrm{kg}$ on days 2 and 3$)$ and primaquine $(0.5 \mathrm{mg} / \mathrm{kg} /$ day, for 7 days $)$, but a normal spleen size was achieved only after weekly administration of chloroquine $(5 \mathrm{mg} / \mathrm{kg} /$ week, for 3 months). Acute febrile syndrome, moderate splenomegaly and thrombocytopenia are sensitive clinical markers for acute malarial infection in endemic areas. However, the finding of large-volume splenomegaly in an afebrile patient must raise the diagnostic suspicion of chronic malaria.

Paciente de 14 anos, previamente saudável, procedente de Maués (Amazonas), iniciou com febre alta diária em dezembro de 2004. Após um mês de doença, a febre se tornou intermitente e 0 paciente ficou afebril em fevereiro de 2005. Várias gotas espessas foram negativas para malária. Havia intensa esplenomegalia ao exame físico. Ultra-sonografia e tomografia computadorizada abdominais evidenciaram aumento homogêneo do fígado e do baço. 0 hemograma mostrou $10 \mathrm{~g} / \mathrm{dL}$ de hemoglobina; 4.800 leucócitos $/ \mathrm{mm}^{3}$ (com linfócitos atípicos); 6.000 plaquetas/ $\mathrm{mm}^{3} ; 0,3 \%$ de reticulócitos; velocidade de hemossedimentação de $68 \mathrm{~mm}$ na primeira hora e bioquímica normal. Repetidas gotas espessas e $\mathrm{QBC}{ }^{\circledast}$ para malária foram novamente negativos. Uma biópsia de medula óssea realizada em março de 2005 revelou hiperplasia megacariocítica e mielóide, sem qualquer evidência de síndrome hemofagocítica. Ao longo desse período, a contagem de plaquetas variou de 3.000 a $24.000 / \mathrm{mm}^{3}$, mas o paciente não referiu nenhum episódio de sangramento. Uma nova avaliação da medula óssea realizada em maio de 2005 mostrou raros esquizontes de Plasmodium vivax dentro das células da linhagem vermelha (Figura A). A fim de confirmar por biologia molecular a espécie envolvida, uma PCR-aninhada foi realizada de amostra de sangue periférico, evidenciando banda típica de Plasmodium vivax de 120 pares de bases, no gel de eletroforese (Figura B). 0 paciente iniciou cloroquina $(10 \mathrm{mg} / \mathrm{kg}$ no dia 1; $7,5 \mathrm{mg} / \mathrm{kg}$ nos dias 2 e 3$)$ e primaquina $(0,5 \mathrm{mg} / \mathrm{kg} / \mathrm{dia}$, por 7 dias), mas o tamanho do baço só voltou ao normal após a administração semanal de cloroquina $(5 \mathrm{mg} / \mathrm{kg} / \mathrm{semana}$, por 3 meses). Síndrome febril aguda, esplenomegalia moderada e plaquetopenia são marcadores clínicos sensíveis de infecção malárica aguda em áreas endêmicas, contudo, o achado de esplenomegalia volumosa em paciente afebril deve levantar a suspeita diagnóstica de malária crônica.

\section{REFERENCES}

1. Lacerda MVG, Oliveira SL, Alecrim MGC. Splenic hematoma in a patient with Plasmodium vivax malaria. Revista da Sociedade Brasileira de Medicina Tropical 40:96-97, 2007

2. Makkar RP, Mukhopadhyay S, Monga A, Gupta AK. Plasmodium vivax malaria presenting with severe thrombocytopenia. Brazilian Journal of Infectious Diseases 6:263-265, 2002.

3. Mirdha BR, Samantray JC, Mishra B, Xess I. Bone marrow examination for identifying malaria in fever of unknown origin. The Journal of the Association of Physicians of India 47:177-179, 1999. 